\title{
The Changing Culture in Modern Medicine: A Psychiatrist's Perspective
}

\author{
Kenneth R. Kaufman* \\ Departments of Psychiatry and Neurology, UMDNJ-Robert Wood Johnson Medical School, 125 Paterson Street, Suite \\ \#2200, New Brunswick, NJ 08901, USA
}

\begin{abstract}
Cultural competence advances global healthcare by promoting greater understanding of individual patients, combined interventions, and maximum adherence. However, the healthcare professional's culture and the culture of medicine itself must also be considered. In westernized medicine, especially America, improved technology and therapeutics profoundly impact medical culture; but medical economics is as significant. Managed care and Medicare Diagnosis-Related Groups (DRGs) strongly affect American medical economics with resultant decreased physicians' incomes, increased patient volumes, decreased time spent with each patient, and decreased subjective/objective quality of care. Physicians' roles blur with duties delegated to lesser qualified healthcare professionals to maximize patients seen and generated incomes. In psychiatry, performing multiple psychopharmacology visits hourly is economically more productive than an hour therapy session. Doctors need to understand that in entering medicine they enter a life's career of nobility in which they serve others, do not expect to become wealthy, but at life's end are able to state "a job well done with caring for all." Perhaps then, less harm will be done to patients in doctors' haste to earn more money by seeing too many patients too briefly.
\end{abstract}

Keywords: Cultural competence, medicine, healthcare, managed care, medicare, drg, economics, profession, business, physician, resident, medical student, satisfaction, dissatisfaction, patient, time pressure, education, ethics, curriculum, psychiatry.

Groups of doctors jammed into elevators maddeningly looking at their lists, checking off those seen and yet to be seen and occasionally looking up toward a colleague and bemoaning how many more consults to be done before the end of the day. When did doctoring stop being a noble profession of caring for others, of having time to care for others, and change so dramatically into making sure that all those who could be billed in a given day were seen and then billed for maximum charges?

In retrospect, one could argue that we as physicians sold our souls to the insurance companies and that over the years the insurance companies realized their power, and having done such also realized that they controlled how much doctors were paid and even if services should be authorized [1]. Managed care companies now manage not only the health of patients but also physicians' lives. With decreased professional autonomy, managed care is associated with decreased physician career satisfaction [2] Authorization must be obtained not simply for admission to a hospital, but for outpatient procedures, for specific medications, and even for dosage of medications [1, 3-5]. Often these authorizations are obtained from individuals with no knowledge of the procedure or medication but reading from a handbook stating what should or should not be approved and taking valuable time from patient care for administrative tasks.

*Address correspondence to this author at the Departments of Psychiatry and Neurology, UMDNJ-Robert Wood Johnson Medical School, 125 Paterson Street, Suite \#2200, New Brunswick, New Jersey 08901, USA; Tel: 732-235-7647; Fax: 732-235-7677; E-mail: kaufmakr@umdnj.edu
With the advent of Medicare Diagnosis-Related Groups (DRGs), hospital admissions in America are focused on the minimum stay for maximum DRG value. Reimbursement inequities for non-stratified DRGs have been noted when comparing complex patients with multiple complications and comorbidities to those patients without complications or comorbid diagnoses leading to greater hospital financial risk [6]. In the past, a patient would have multiple diagnoses, including non-related but significant diagnoses that might be treated in an outpatient setting, addressed in a single admission; now patients are told to come back after one week so that they can have other diagnoses attended to in an inpatient setting such that the hospital is not penalized by Medicare or managed care insurance companies for the patient "bouncing-back" too early or having stayed too long during the original admission wherein the hospital instead of earning money lost money [7]. Outcome managers now focus on length of stay and outliers instead of quality of care and premature discharge; yet early hospital discharge may be associated with preventable readmissions in specific populations [8-10].

As physicians' reimbursements decrease, their hospital lists increase, and less time is spent with each patient. When you speak to colleagues at $8 \mathrm{pm}$ or $9 \mathrm{pm}$ after they have been seeing patients for 13 hours you will hear the same litany, "where did medicine go wrong... what happened to quality medical care... why doesn't the hospital provide more services...I need this drug, why isn't it on the formulary...I have to stop talking; I have more patients to see!" Doctor discontent and time pressures are significant problems in our new medico-economic environment impacting physician satisfaction, patient satisfaction, and quality of care $[11,12]$.

Often, the patient's perception of quality of care is directly related to the time physicians spend addressing medical com- 
plexities $[13,14]$. With the current decreased time physicians spend with each patient, is it surprising that patients perceive a crisis in quality of care?

In psychiatry, we have both the luxury and the requirement that we spend time, and by that is meant adequate time, with patients. In the consultation-liaison setting, how often have you heard the patient state "at least you listen to me, my other doctors come in at 6 am, I was still sleeping when they told me about my illness; they told me not to worry and that they would need to do some chemotherapy that would make me better?" But did the oncologist discuss in detail with that patient chemotherapy, prognosis, quality of life, and also have a family session? Not always; frequently psychiatric consultation is requested in that and other "messy" situations; the attending internist comments about the "emotional train wrecks" that "would just take too much of my time, you are better skilled at talking to patients that I am." How often have you been requested to assist with "termination and closure" when the patient knew neither the diagnosis nor the proximity of death?

What of the consent forms for surgery obtained by nurses as the patient is prepping for the Operating Room (OR), and sometimes on the gurney being wheeled toward the OR? Consent requires the understanding of alternatives/ benefits/ risks; however, if these have not been adequately explained to the patient, then that patient, who otherwise might have the capacity to make an informed decision, cannot make an informed decision simply because he does not have the appropriate information. Have you ever been called to do a competency consultation because nursing was concerned that the patient did not truly understand the gravity of the procedure, do the consult finding the patient did not have capacity to make an informed consent, advise the surgeon and anesthesiologist of such, but then witness the elective surgery being done anyway?

Even in psychiatry, the roles are blurred. Where once the psychiatrist did psychotherapy and psychopharmacology, now there are psychiatrists who believe their strict role is only psychopharmacology and that therapy should be done by others - social workers, nurses, pastoral counselors, or psychologists. It goes without saying that in sixty minutes, a psychiatrist can bill and collect more from multiple psychopharmacology sessions than he/she can from a single combined psychotherapy and psychopharmacology session [15].

So what will happen in the future? When we discuss "medical culture" we are often addressing therapeutic and technological advances in medicine and how these impact patient care; but "medical culture" also involves how we address medical problems, what we believe is possible to accomplish, and even our perceptions of positive prognosis [16]. Patients may not understand any of this. Why is there this lack of understanding? Could it simply be because we do not spend enough time with our patients and the patient's family? The therapeutic/ technical revolution in medicine with emphasis on data and evidenced-based treatments distances physicians from their patients and diminishes the fundamental traits that led students to enter medical school, caring and empathy [17]. Have we lost focus in educating our medical students and residents [17-19]? The dark undercurrents to the meaning of medical culture are the economic aspects associated with being a health care provider, time consuming, nearly adversarial interactions with insurance companies to obtain necessary authorizations with associated appeals, and witnessing a once noble profession being changed into a "business." To what extent have these undercurrents eroded patient trust and confidence in the physician?

Are there solutions for an American healthcare system now in crisis beyond best practice guidelines with outcome research and multidisciplinary team interventions to maximize quality of care, efficiency, and safety [20-22]? Certainly patients would like medical care to be as it once was. But this may mean: 1) accepting single payer national health systems/ universal insurance in which for once healthcare professionals are truly insurance blind and uninsured patients finally have appropriate healthcare coverage [23-25]; 2) allowing procedures and medications at reduced costs without excessive physician administrative time wasted, especially medication prior authorizations, at the expense of patient care [26-28]; 3) having pharmaceutical companies realize that capitalism includes the critical first three letters "cap" and applying such while, with the assistance of indexed state and federal tax incentives, maintaining research and development to pursue further innovative therapeutics [29-31]; 4) maximizing transparency in research with publication of all conflicts of interest to ensure an unbiased presentation of information to both healthcare professionals and the public [32-34]; 5) having nonprofit hospitals remaining not for profit rather than hiding excess earnings in land purchases; 6) minimizing / eliminating medical student indebtedness with combined federal funding to medical schools for undergraduate medical education, increased federal scholarships to students, increased medical school scholarships, decreased medical school tuition, and tax incentive loans for medical school education [35-40]; 7) restructuring medical school, residency, and continuing medical education curricula to address humanism/ ethics/values/ culture of caring [16-19, 41-49]; 8) and finally having doctors understand that in entering medicine you enter a life's career of nobility in which you serve others and do not expect to become wealthy, but at life's end are able to state "a job well done with caring for all."

One might say that this is beating an old drum or simply the voice of another healthcare professional calling in the wilderness. Perhaps, but hopefully someone will hear this fervent call to action. Appropriate restructuring of our medical education and health service delivery systems while focusing on ethics/values/ and the patient-physician relationship should improve quality of care, efficiency, safety, patient / physician satisfaction, patients' trust and the physician's pride in being a doctor.

Each physician takes an oath not simply to aid his patient, but specifically "to do no harm [50-52]." As our current medical culture exists, harm occurs all too often.

\section{ACKNOWLEDGEMENTS}

There are no conflicts of interest. 


\section{REFERENCES}

[1] Kaufman KR. Academic and private practice medicine and health service delivery systems: A psychiatric commentary. Ann Clin Psychiatry 2000; 12(3): 175-7.

[2] Stoddard JJ, Hargraves JL, Reed M, Vratil A. Managed care, professional autonomy, and income: effects on physician career satisfaction. J Gen Intern Med 2001; 16(10): 675-84.

[3] Sandifer QD. Managing care. J Public Health Med 1997; 19(3): 301-6.

[4] Law MR, Ross-Degnan D, Soumerai SB. Effect of prior authorization of second-generation antipsychotic agents on pharmacy utilization and reimbursements. Psychiatr Serv 2008; 59(5): 5406.

[5] Huskamp HA. Pharmaceutical cost management and access to psychotropic drugs: the U.S. context. Int J Law Psychiatry 2005; 28(5): 484-95.

[6] Munoz E, Barrau L, Goldstein J, Benacquista T, Mulloy K, Wise L. DRG prospective, "all payor systems" financial risk, and hospital cost in pulmonary medicine non CC stratified DRGs. Chest 1988; 94(4): 855-61.

[7] Empire. 3. Claims, Billings \& Reimbursements. [accessed on 7 June 2008] Available at:

http://www.empireblue.com/provider/noapplication/f4/s1/t0/pw_ ad068127.pdf

[8] Wickizer TM, Lessler D. Do treatment restrictions imposed by utilization management increase the likelihood of readmission for psychiatric patients? Med Care 1998; 36(6): 844-50.

[9] Experton B, Ozminkowski RJ, Pearlman DN, Li Z, Thompson S. How does managed care manage the frail elderly? The case of hospital readmissions in fee-for-service versus HMO systems. Am J Prev Med 1999; 16(3): 163-72.

[10] Lessler DS, Wickizer TM. The impact of utilization management on readmissions among patients with cardiovascular disease. Health Serv Res 2000; 34(6): 1315-29.

[11] Haas JS. Physician discontent: a barometer of change and need for intervention. J Gen Intern Med 2001; 16(7): 496-7.

[12] Linzer M, Konrad TR, Douglas J, et al. Managed care, time pressure, and physician job satisfaction: results from the physician worklife study. J Gen Intern Med 2000; 15(7): 441-50.

[13] Geraghty EM, Franks P, Kravitz RL. Primary care visit length, quality, and satisfaction for standardized patients with depression. J Gen Intern Med 2007; 22(12): 1641-7.

[14] Katz JN, Kessler CL, O'Connell A, Levine SA. Professionalism and evolving concepts of quality. J Gen Intern Med 2007; 22(1): 137-9.

[15] Kaufman KR. Problems with the electronic medical record in clinical psychiatry: a hidden cost. J Psychiatr Pract 2005; 11(3): 200-4.

[16] Fox RC. Cultural competence and the culture of medicine. N Engl J Med 2005; 353(13): 1316-9.

[17] Cooper RA, Tauber AI. Viewpoint: new physicians for a new century. Acad Med 2005; 80(12): 1086-8.

[18] Cooper RA, Tauber AI. Values and ethics: a collection of curricular reforms for a new generation of physicians. Acad Med 2007; 82(4): 321-3.

[19] Dobie S. Viewpoint: reflections on a well-traveled path: selfawareness, mindful practice, and relationship-centered care as foundations for medical education. Acad Med 2007; 82(4): 4227.

[20] Lofgren R, Karpf M, Perman J, Higdon CM. The U.S. health care system is in crisis: implications for academic medical centers and their missions. Acad Med 2006; 81(8): 713-20.

[21] Karpf M, Schultze RG, Levey G. The decade of the nineties at the UCLA Medical Center: responses to dramatic marketplace changes. Acad Med 2000; 75(8): 781-92.

[22] Corrigan JM, Donaldson MS, Kohn LT, Eds. Crossing the quality chasm: A new health system for the $21^{\text {st }}$ century. Washington, DC: National Academy Press 2001.

[23] McCormick D, Himmelstein DU, Woolhandler S, Bor DH Single-payer national health insurance. Physicians' views. Arch Intern Med 2004; 164(3): 300-4.

[24] Sarpel U, Vladeck BC, Divino CM, Klotman PE. Fact and fiction: debunking myths in the US healthcare system. Ann Surg 2008; 247(4): 563-9.
[25] The Physicians' Working Group for Single-Payer National Health Insurance. Proposal of the physicians' working group for singlepayer national health insurance. JAMA 2003; 290(6): 798-805.

[26] Balkrishnan R, Joish VN, Bhosle MJ, Rasu RS, Nahata MC. Prior authorization of newer insomnia medications in managed care: is it cost saving? J Clin Sleep Med 2007; 3(4): 393-8.

[27] Ketcham JD, Epstein AJ. Medicaid preferred drug lists' costs to physicians. Med Care 2008; 46(1): 9-16.

[28] Tynan A, Berenson RA, Christianson JB. Health plans target advanced imagining services: cost, quality and safety concerns prompt renewed oversight. Issue Brief Cent Stud Health Syst Change 2008; 118: 1-4

[29] American Medical Student Association. The pharmaceutical industry: profits before people. [accessed on 17 June 2008] Available at: www.amsa.org/pdf/will.PDF

[30] Emanuel EJ, Fuchs VR. The perfect storm of overutilization. JAMA 2008; 299(23): 2789-91.

[31] Rosenberg-Yunger ZR, Daar AS, Singer PA, Martin DK. Healthcare sustainability and the challenges of innovation to biopharmaceuticals in Canada. Health Policy 2008 (in press); doi:10.1016/j. healthpol. 2008.02.004

[32] Rampton S, Stauber J. Research funding, conflicts of interest, and the "meta-methodology" of public relations. Public Health Rep 2002; 117(4): 331-9.

[33] Baird P. Getting it right: industry sponsorship and medical research. CMAJ 2003; 168(10):1267-9.

[34] Moher D, Simera I, Schulz KF, Hoey J, Altman DG. Helping editors, peer reviewers, and authors improve the clarity, completeness, and transparency of reporting health research. BMC Med 2008; 6(1): 13; doi:10.1186/1741-7015-6-13.

[35] American Medical Association. 2003 Report of the American Medical Association - Medical Student Section Task Force on Medical Student Debt. Final Draft. [accessed on 21 June 2008] Available at:

www.ama-assn.org/ama1/pub/upload/mm/debt15_report.pdf

[36] American Medical Association. Medical student debt. [accessed on 21 June 2008] Available at:

www.ama-assn.org/ama/pub/category/57349.html

[37] Kassebaum DG, Szenas PL, Schuchert MK. On rising medical student debt: in for a penny, in for a pound. Acad Med 1996; 71(10): 1124-34.

[38] Jolly P. Medical school tuition and young physicians' indebtedness. Health Aff (Millwood) 2005; 24(2): 527-35.

[39] Clark K. How to go to medical school for free. US News \& World Report. [accessed on 22 June 2008] Available at: www.usnews.com/articles/business/paying-for-graduateschool/2008/06/02/how-to-go-to-medical-school-for-free.html

[40] IRS. Publication 970 (2007): Tax benefits for education. [accessed on 22 June 2008] Available at: www.irs.gov/pub/irs-pdf/p970.pdf

[41] Branch WT Jr, Kern D, Haidet P, et al. The patient-physician relationship. Teaching the human dimensions of care in clinical settings. JAMA 2001; 286(9): 1067-74.

[42] Christianson CE, McBride RB, Vari RC, et al. From traditional to patient-centered learning: curriculum change as an intervention for changing institutional culture and promoting professionalism in undergraduate medical education. Acad Med 2007; 82(11): 1079-88.

[43] Boutin-Foster C, Foster JC, Konopasek K. Viewpoint: physician, know thyself: the professional culture of medicine as a framework for teaching cultural competence. Acad Med 2008; 83(1): 106-11.

[44] Buetow S, Elwyn G. The window-mirror: a new model of the patientphysician relationship. Open Med 2008; 2(1): E20-25.

[45] Surbone A. Cultural aspects of communication in cancer care. Support Care Cancer 2008; 16(3): 235-40.

[46] Bercovitch L, Long TP. Dermatoethics: a curriculum in bioethics and professionalism for dermatology residents at Brown Medical School. J Am Acad Dermatol 2007; 56(4): 679-82.

[47] Shapiro J, Rucker L, Robitshek D. Teaching the art of doctoring: an innovative medical student elective. Med Teach 2006; 28(1): 30-5.

[48] Kanter SL, Wimmers PF, Levine AS. In-depth learning: one school's initiatives to foster integration of ethics, values, and the human dimensions of medicine. Acad Med 2007; 82(4): 405-9.

[49] Salas-Lopez D, Holmes LJ, Mouzon DM, Soto-Greene M. Cultural competence in New Jersey: evolution from planning to law. J Health Care Poor Underserved 2007; 18(1): 35-43.

[50] Kaufman KR. Comparative bioethics in bipolar and epilepsy research. Seizure 2002; 11(1): 51- 6 . 
[51] Smith CM. Origin and uses of primum non nocere - above all, do no harm! J Clin Pharmacol 2005; 45(4): 371-7.
[52] Davey LM. The oath of Hippocrates: an historical review. Neurosurgery 2001; 49(3): 554-6.

Received: March 25, 2008

Revised: May 28, 2008

Accepted: June 26, 2008

(c) Kenneth R. Kaufman; Licensee Bentham Open.

This is an open access article licensed under the terms of the Creative Commons Attribution Non-Commercial License (http://creativecommons.org/licenses/bync/3.0/), which permits unrestricted, non-commercial use, distribution and reproduction in any medium, provided the work is properly cited. 